УДК: 616.132.2:616.12-008.313.2

DOI: 10.18101/2306-1995-2019-3-56-62

\title{
КЛИНИЧЕСКИЙ СЛУЧАЙ КОМБИНИРОВАННОЙ АНТИТРОМБОТИЧЕСКОЙ ТЕРАПИИ ПРИ ОСТРОМ КОРОНАРНОМ СИНДРОМЕ С ФИБРИЛЛЯЦИЕЙ ПРЕДСЕРДИЙ
}

\author{
(C) Содномова Лариса Балдановна \\ старший преподаватель, \\ Бурятский государственный университет им. Д. Банзарова \\ Россия, 670002, г. Улан-Удэ, ул. Октябрьская, 36а \\ тел: 8(3012) 44-55-03, +7 (983) 429-30-72 \\ E-mail: Lar43099701@yandex.ru
}

В клинической практике часто имеет место коморбидность фибрилляции предсердий (ФП) и острого коронарного синдрома (ОКС). В лечении ОКС ведущее место занимает двойная антиагрегантная терапия (ДАТ). Наличие ФП диктует необходимость профилактики тромбоэмболических осложнений (ТЭО) посредством назначения оральных антикоагулянтов (ОАК). При наличии одновременных показаний к приему антиагрегантных средств и перорального антикоагулянта необходимо выбрать оптимальную комбинацию, взвешивая преимущества и риски такой достаточно агрессивной антитромботической терапии. Арсенал антиагрегантов и оральных антикоагулянтов за последнее время значительно расширился, опубликованы результаты исследований по антитромботической эффективности и безопасности новых оральных антикоагулянтов у пациентов с ФП, разных комбинаций антиагрегантов в рамках двойной антиагрегантной терапии (ДАТ) при ОКС, разных комбинаций антиагрегантов и антикоагулянтов при ОКС у пациента с ФП. В каждом клиническом случае сочетанной патологии ОКС и ФП врачу предстоит реализовывать персонифицированный подход при назначении комбинированной ААТ.

Ключевые слова: острый коронарный синдром; фибрилляция предсердий; антитроботическая терапия; антиагрегантная терапия; тромбоэмболические осложнения; двойная антиагрегантная терапия; оральный антикоагулянт.

\section{Для цитирования}

Содномова Л. Б. Клинический случай комбинированной антитромботической терапии при остром коронарном синдроме с фибрилляцией предсердий // Вестник Бурятского государственного университета. Медицина и фармация. 2019. Вып. 3. C. 56-62.

Фибрилляция предсердий регистрируется у каждого 5-го больного с ОКС. При ОКС в сочетании с ФП 30-дневная летальность возрастает в два раза по сравнению с синусовым ритмом. При ранее существовавшей ФП смертность возрастает на $28 \%$, при остроразвившейся ФП - на $37 \%$ [10, 11]. При ОКС рекомендована двойная антиагрегантная терапия, включающая помимо ацетилсалициловой кислоты ингибиторы Р2Y12 рецепторов тромбоцитов, арсенал которых помимо клопидогреля пополнился в последнее время тикагрелором, прасугрелем [5]. ФП повышает риск развития инсульта в 5 раз, профилактика ТЭО при ФП занимает одну из ключевых позиций ведения пациента и предполагает назначение оральных антикоагулянтов [2]. ОАК в виде монотерапии не предупреждают стент-тромбозы и ишемические события при ОКС. 
Л. Б. Содномова. Клинический случай комбинированной антитромботической терапии при остром коронарном синдроме с фибрилляцией предсердий

Соответственно пациент с ОКС и ФП получает комбинированную антитромботическую терапию - антиагрегантную и антикоагулянтную [1, 3]. Из оральных антикоагулянтов наиболее известен антагонист витамина К варфарин, однако ввиду сложностей удержания контролируемого показателя МНО в терапевтическом диапазоне врачи все больше при ФП назначают новые оральные антикоагулянты (НОАК) [6, 8]. Последние в разных дозах демонстрируют в сравнении с варфарином аналогичную или превосходящую эффективность и однозначно лучшую безопасность. Из них наиболее действенным для профилактики кардиоэмболического инсульта у больных с ФП по результатам непрямого сравнительного анализа оказался ингибитор II фактора свертывания крови дабигатрана этексилат [4]. В составе тройной ААТ препарат назначается в дозе 110 мг х 2 раза в день. По результатам сравнительного исследования REDUALPCI тройная и двойная AAT $\mathrm{c}$ включением дабигатрана этексилата имели аналогичную эффективность, однако двойная схема ожидаемо показала лучшую безопасность [9]. Еще одним существенным преимуществом использования дабигатрана этексилата является наличие у него антидота идаруцизумаба (праксбайнда) при развитии геморрагических осложнений. Для иллюстрации сложностей антитромботической терапии относительно баланса между эффективностью и безопасностью приводится клинический случай пациентки с коморбидной патологией, у которой реализовалась комбинированная ААТ с послеоперационным геморрагическим осложнением.

Пациентка Д., 64 г., поступила в отделение неотложной кардиологии с жалобами на давящие боли в грудной клетке без четкого эффекта от нитроспрея, выраженную одышку, сердцебиение.

\section{История заболевания}

Гипертоническая болезнь в течение ряда лет с максимальным повышением САД до 180 мм рт. ст. адаптирована к АД 110-120/80 мм рт. ст. ОНМК по ишемическому типу перенесла в 2013 г., лечилась в стационаре по месту жительства. Нарушение ритма наблюдается с 2014 г. по типу ФП, пароксизмальной формы. Боли в грудной клетке и одышку отмечает в последние 4-5 лет с явным ограничением физической активности в течение последнего года, с этого же времени стали беспокоить слабость, частое головокружение. Состоит на диспансерном учете по месту жительства. Лекарственные препараты на амбулаторном этапе принимала в следующем объёме: торасемид 5 мг, аторис, кардиомагнил, панангин. Примерно год назад прекратила прием пульсурежающих препаратов ввиду склонности к брадикардии до 38/мин. Настоящее ухудшение состояния случилось два часа назад, появились давящие боли за грудиной, выраженная одышка в покое, сердцебиение. Бригада СМП вызвана в связи с ангинальными болями, усилением одышки, невозможностью нахождения в горизонтальном положении. Снята ЭКГ, которая отразила фибрилляцию предсердий с ЧСС 125 в минуту, признаки субэндокардиальной ишемии миокарда переднебоковой стенки левого желудочка, ПБПНПГ. В сравнении с ЭКГ-архивом рецидив ФП, депрессия сегмента ST в V3-6, I, AVL-отведениях. ПБПНПГ 
регистрируется с 2015 г. АД по «03» 100/60 мм рт. ст. По СМП проведено лечение в объёме: в таблетках аспирин 250 мг, гепарин 4000 Ед в/в стр на физрастворе $0,9 \%, 10,0$ мл, клопидогрель 300 мг, раствор кордарона 300 мг в/в капельно. В приемном покое пациент(ка) осмотрена кардиологом, госпитализирована в стационар.

Семейный анамнез - наследственность отягощена ГБ, СД, сопутствующие заболевания - сахарный диабет 2-го типа выявлен в 2013 г., принимала диабетон, хронический гастрит.

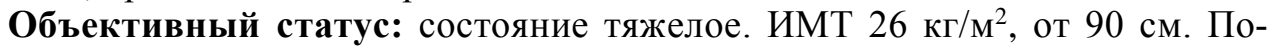
ложение ортопноэ. Кожные покровы бледные, повышенной влажности. Периферических отеков на ногах нет. Пульсация на артериях нижних конечностей практически не определяется. Грудная клетка обычной формы. В легких дыхание везикулярное, ослабленное в нижних отделах, здесь же крепититрующие хрипы. ЧД 28-34 в мин. Ритм сердца неправильный, ЧСС 108-134 в мин, АД 108/70 мм рт. ст. Живот мягкий, безболезненный. Печень по краю реберной дуги. Мочеиспускаение свободное, диурез со слов адекватный.

Диагноз: ИБС. Нестабильная стенокардия. KillipII. CССУ. Синдром бради-тахикардии. СА блокада 2-3-й степени, преходящий узловой ритм, НЖЭС с длинными постэкстрасистолическими паузами, заместительными узловыми комплексами. Рецидивирующая фибрилляция предсердий с преходящей асистолией (до 4840 мс), заместительными узловыми комплексами. EHRAIV, CHA2DS2-VASC -8 баллов, HASBLED - 4 балла. Предвестники MЭС. Имплантация постоянного ЭКС 460 DR с переводом работы в режим VVI. Полная блокада правой ножки пучка Гиса. ХСН с низкой ФВ (35\%), стадия ІІБ, ФК III. Явления ОЛЖН. Двусторонний гидроторакс. Гипертоническая болезнь III стадии, АГ 1-й степени, риск 4 (абдоминальное ожирение, дислипидемия, гиперурикемия, СКФ 47 мл/мин, ГЛЖ, СД, ОНМК, периферический атеросклероз, КР, стенокардия). Сахарный диабет 2-го типа, целевые цифры гликированного гемоглобина менее $8,0 \%$, с множественными поздними осложнениями. Диабетическая нефропатия. Кисты левой почки. ХБП СЗаА2. Атеросклероз сосудов нижних конечностей. Окклюзия ПБА, ПКА с обеих сторон. ХИНК 2б. Состояние после ОНМК в 2013 г. Хронический субатрофический гастрит с единичной эрозией в антральном отделе желудка. Железодефицитная анемия легкой степени тяжести.

Диагноз выставлен на основании:

1) острого коронарного синдрома (ангинальный статус в грудной клетке, ЭКГ-признаки субэндокардиальной ишемии миокарда передне-боковой стенки ЛЖ, ЭхоКГ - гипокинез апикальных сегментов передней, боковой стенок ЛЖ, КАГ — артины — протяженный стеноз пр/3, ср/3 до 80-90\% (вероятнее хронического характера), ОА критический стеноз пр/3. ПКА протяженный стеноз пр/3 до $30-40 \%$, неровности контуров д/3, без гемодинамически значимого стенозирования);

2) синдрома нарушений ритма сердца и проводимости - синдром брадитахикардии (урежение пульса до 38 в мин и, наоборот, приступы частого нерегулярного сердцебиения, серия ЭКГ - СА блокада 2-3-й степени, в динамике ФП, результаты суточной ЭКГ (минимальная частота 41-56 уд. в 
Л. Б. Содномова. Клинический случай комбинированной антитромботической терапии при остром коронарном синдроме с фибрилляцией предсердий

мин, максимальная частота сердечных сокращений - 156 уд. в мин, непрерывно рецидивирующие пароксизмы ФП с частотой для желудочков 72-156 уд. в мин. с паузами при попытке восстановления ритма, появлением заместительных узловых комплексов. Пауз более 2000 м с - 5. Максим. RR - 4840 м с (23:12 час.). ЖЭС (105) - одиночные, политопные. Полная блокада правой н. п. Гиса. + Вторичные нарушения пр. реполяризации;

3) синдрома сердечной недостаточности (выраженная одышка с переходом в удушье при поступлении, ранее отеки на ногах, физикально тахипноэ с ЧДД 34-28 в мин, ослабление везикулярного дыхания в нижних отделах легких, крепитирующие хрипы здесь же, NT-proBNP 1543, по ЭхоКГ данным диффузный гипокинез. Снижение глобальной систолической функции ЛЖ. ФВ 35\%. Диастолическая дисфункция ЛЖ по 2-му типу. Расчетное давление в ЛА 75 мм рт. ст. Свободная жидкость в плевральных полостях);

4) синдрома кардиомегалии (по ЭхоКГ дилатация ЛП, правых отделов сердца, МН 3, ТН 2-3. Гипертрофия миокарда ЛЖ. ИММЛЖ - 192,1 г/м²);

5) синдрома ишемии нижних конечностей (боли в ногах, ослабление пульсации на артериях нижних конечностей, УЗДГ артерий н/к окклюзирующий атеросклероз ПБА, ПКА с обеих сторон);

6) синдрома железодефицитной анемии (слабость, снижение красных показателей крови и сывороточного железа (гемоглобин 98 г/л, сывороточное железо 5 мкм/л);

7) данных ЭГДС желудка (гастрит, эрозия желудка);

8) нарушение углеводного обмена (анамнез СД).

Проведено лечение: диета № 9, режим расширен до ІІІБ, ацетилсалициловая кислота 75 мг вечером с отменой, таблетки клопидогреля 75 мг вечером, раствор эноксапарина (клексана) 0,6 мл х 2 раза в день подкожно с переходом на дабигатрана этексилат 110 мг х 2 раза в день с временной отменой из-за геморрагического пропитывания послеоперационного ложа, аторвастатин 80 мг, затем 40 мг вечером, спиронолактон 25 мг х 1 раз в день утром, фуросемид 40-20 мг в/в капельно, торасемид 40 мг х 1 раз в день утром, к. омепразол 20 мг х 2 раза в день, вентер 1000 мг х 2 раза в день, кордарон 200 мг х 3 раза в день после имплантации ЭКС, раствор цефазолина 500 мгх 1 раз в день в/в, раствор актрапида 6-4-4 ед подкожно, раствор протафана в 8 ч 8 ед подкожно, 22 ч 4 ед подкожно.

На фоне проведенного лечения состояние улучшилось - уменьшились проявления СН (одышка, жидкость в плевральных полостях редуцировалась), ангинальные боли в грудной клетке не рецидивировали, частота сердечных сокращений регулирована на уровне 60-115 в мин, по ЭКГ синусовый ритм с пароксизмами ФП, работа ЭКС VVI в режиме по требованию.

Выписана с рекомендациями: диета 9, дабигатрана этексилат 110 мг х 2 раза в день неопределенного долго, клопидогрель 75 мг х 1 раз в день в течение 12 месяцев, аторвастатин 40 мг х 1 раз в день, кордарон 200 мг х 3 раза в день до 10 г с переходом на поддерживающую дозу 200 мг/сут., периндоприла аргинин 10 мг, спиронолактон 25 мг х 1 раза в день утром, торасемид 40 мг х 1 раза в день утром, к. омепразол 20 мг х 2 раза в день, 
инсулинотерапия под контролем гликемии, реваскуляризация артерий нижних конечностей в плановом порядке

Обсуждение: в описываемом клиническом случае у пациентки имелся ОКСбезп ST высокого риска госпитальной смерти, прогноз отягощал коморбидный фон - дисфункция синусового узла с предвестниками МЭС, затяжными пароксизмами тахисистолической ФП, СД, ХСНнФВ (35\%), окклюзирующий атеросклероз артерий нижних конечностей, ХИНК 2Б. ХБП СЗаА0 (СКФ 47 мл/мин), хронический субатрофический гастрит с эрозией в антральном отделе желудка, железодефицитная анемия. Согласно рекомендациям по реваскуляризации миокарда 2018 г., пациентка нуждалась в проведении экстренного АКШ, однако ввиду высокого операционного риска при проведении открытой операции проведено чрескожное вмешательство (ЧКВ) - коронарная реваскуляризация (КР), стентирование коронарной артерии. У пациентки имелся риск тромбоза имплантированного стента, риск повторного инсульта и других эмболических осложнений на фоне ФП с высоким баллом по шкале CHA2DS2-VASC, что обязывало проводить тройную антитромботическую терапию (ДАТ и антикоагулянтную), сопровождающуюся соответственно высоким риском геморрагических осложнений. Согласно Европейским рекомендациям по ЭКС и СРТ от 2013 г. пациентка нуждалась в имплантации ЭКС с учетом симптомной брадиаритмии и необходимости контроля частых рецидивов ФП. Наличие ХБПСЗа, гастрита с эрозией повышает риск геморрагических осложнений на фоне проведения массивной антитромботической терапии, который реализовался в локальном геморрагическом осложнении в послеоперационном периоде после имплантации ЭКС (пропитывании ложа ЭКС и длительном заживлении послеоперационной раны). В данном случае возможным шагом для снижения риска кровотечений было сокращение тройной ATT до двойной с учетом результатов исследования REDUALPCI, а также актуальным представлялось применение антидота дабигатрана этексилата идаруцизумаба (прайс-байнда) перед оперативным вмешательством, которое не имело реализации ввиду его отсутствия в стационаре.

\section{Выводы}

1. Коморбидная патология у пациента с ОКС и ФП имеет следствие в виде повышения риска как тромботических, так и геморрагических осложнений, что требует выбора оптимальной антитромботической комбинации. Подобной комбинацией может быть двойная ААТ с дабигатрана этексилатом (доза выбирается в зависимости от риска кровотечений) и клопидогрелем.

2. Использование антидота дабигатрана этексилата идаруцизумаба (прайс-байнда) позволит нейтрализовать эффект препарата на время оперативного вмешательства и раннего послеоперационного периода, что не реализовалось в описанном случае ввиду его отсутствия в наличии. 
Л. Б. Содномова. Клинический случай комбинированной антитромботической терапии при остром коронарном синдроме с фибрилляцией предсердий

Лuтература

1. Воробьева Н. М., Панченко Е. П. Профилактика тромбоэмболических осложнений у пациентов с фибрилляцией предсердий после стентирования коронарных артерий // Атеротромбоз. 2015. № 1. С. 2-14.

2. Диагностика и лечение фибрилляции предсердий. Рекомендации РКО, ВНОА, ACCX, 2017. webmed.irkutsk.ru

3. Козиолова Н. А., Суровцева М. В. Подходы к выбору антикоагулянтной терапии у больных с неклапанной фибрилляцией предсердий и ишемической болезнью сердца // Кардиоваскулярная терапия и профилактика. 2016. № 15 (2). С. 83-92.

4. Панченко Е. П. Эффективность и безопасность дабигатрана у пожилых больных с неклапанной фибрилляцией предсердий в реальной клинической практике (результаты исследования MEDICARE) // Атеротромбоз. 2015. № 1. C. 31-38.

5. Рекомендации ESC по ведению пациента с острым коронарным синдромом без стойкого подъема сегмента ST, 2017 г. - escardio. ru

6. Антикоагулянтная терапия у пациентов с фибрилляцией предсердий: состояние проблемы в рутинной клиническорй практике / А. А. Соколова, И. Л. Царев, Д. А. Напалков, В. А. Сулимов // Трудный пациент. 2015. Т. 13. № 7.

7. Шахматова О. О., Панченко Е. П. Как снизить риск кровотечения при чрескожных коронарных вмешательствах у пациентов с фибрилляцией предсердий: уроки рандомизированных исследований и новые клинические рекомендации // Атеротромбоз. 2018. № 1. С. 93-105.

8. Острый коронарный синдром у пациентов $\mathrm{c}$ фибрилляцией предсердий: возможности использования современных антикоагулянтов / П. Г. Шахнович, Д. О. Балахнов, Д. В. Черкашин, А. Е. Аланичев // Артериальная гипертензия. 2014. Т. 20. № 5. С. 361-368.

9. Cannon CP. RE-DUAL PCI: Dual Antithrombotic Therapy with Dabigatran after percutaneous Coronary Intervention in Patients with Atrial Fibrillation, ESC Congress, Barcelona, 2017, Abstract 1920.

10. Short- and long-term outcomes following atrial fibrillation in patients with acute coronary syndromes with or without ST-segment elevation / R. D. Lopes, K. S. Pieper, J. R. Horton et al. // Heart. 2008. Vol. 94. № 7. P. 867-873.

11. Trends in atrial fibrillation complicating acute myocardial infarction / J. S. Saczynski, D. McManus, Z. Zhou et al. // Am. J.Cardiol. 2009. Vol. 104. № 2. P. 169-174.

\title{
CLINICAL CASE OF THE COMBINED ANTITHROMBOTIC THERAPY IN CASE OF ACUTE CORONARY SYNDROME WITH ATRIAL FIBRILLATION
}

\author{
Larisa B. Sodnomova \\ Senior Lecturer, Medical Institute, \\ Dorzhi Banzarov Buryat State University \\ 36a, Oktyabrskaya st., Ulan-Ude, 670002, Russia \\ Tel.: +73012445503,+79834293072 \\ E-mail: Lar43099701@yandex.ru
}

The comorbidity of atrial fibrillation (AF) and acute coronary syndrome (ACS) often occurs in clinical practice. The treatment of ACS prescribes double antiplatelet therapy (DAT). The presence of AF makes it necessary to prevent thromboembolic complications (FS) through the appointment of oral anticoagulants (UAC). In the presence of simultaneous indications for taking antiplatelet agents and oral anticoagulant, it is necessary to choose the optimal combination. The number of antiplatelet agents 
and oral anticoagulants has recently expanded significantly, the results of studies on the antithrombotic efficacy and safety of new oral anticoagulants in patients with AF, different combinations of antiplatelet agents in dual antiplatelet therapy (DAP) in ACS, different combinations of antiplatelet agents and anticoagulants in ACS in a patient with AF have been published. In each clinical case of combined pathology of ACS and AF, the doctor has to implement a personalized approach when prescribing combined AAT.

Keywords: acute coronary syndrome, atrial fibrillation, antithrombotic therapy, antiplatelet therapy, thromboembolic complications, double antiplatelet therapy, oral anticoagulant. 